\title{
Creating a forestry language $\mathrm{e}^{1}$
}

\author{
by Fred Pinto
}

\section{Introduction}

Some economists suggest that the current economic boom in North America is a result of the use of information and communication technology. They say that information technology has resulted in increasing productivity and lowering of costs. For example, information technology has allowed firms to practice just-in-time delivery and manufacture. Controlling production and inventories is information-intensive, workers require regular updates on the status of production capabilities and the market. Continual reductions in information costs have enabled firms to institute processes that enable their employees to obtain this vital information resulting in reducing waste, improving cash flow, and reducing or eliminating inventory costs. These factors are believed to have contributed to keeping inflation in check,

Chair, Information Technology Working Group Canadian Institute of Forestry/Institut forestier du Canada

munication technology allows us the unprecedented ability to capture, retrieve, distribute, and manipulate data by almost any literate individual with access to a computer.

Large proportions of people and firms in the industrialised world now have the ability to access and create information they need to meet their needs and desires. As people har-

ness the power of information technology to meet their wants, they are causing a fundamental change in how people live, work and perceive their world, employment robust, exports healthy and the cost of borrowing low. Is this scenario true? We will not know for sure until a few more years pass when we can use the 20/20 vision that history provides to analyse the causes of our current economic good fortune.

\section{Understanding the Role of Knowledge in Human Development}

To understand the current information and communication revolution we need to step back in history and look at how information influenced human development. Early humans used oral communications to assist in hunter-gatherer societies. Their knowledge base was the tribal or family memory. Application of this learning allowed their group to take advantage of past successes in hunting, gathering, family care and confrontations with other people, the elements or animals.

The advent of writing is closely related to the move to agriculture and the building of the first cities. For example, Mahandrappa in the Indus valley was the site of one of the oldest human cities. It is also the site of clay tokens thought to be the precursor of writing. It is suggested that the clay tokens were used as a form of accounting in one of humankind's first large marketplaces. Writing found in Sumeria, Egypt, China and elsewhere are all related to sophisticated agricultural societies. Writing allowed societies to capture information and make it available to many more individuals both in the present and the future.

The development of the printing press in Europe made information available to an even greater number of people. This invention and later innovations in copying text and images reduced the cost of reproducing information. Printing played an important role in the industrial revolution that followed. Imagine building and running a railway system or a pulp mill without the ability to print or copy blue prints, operating instructions, schedules, or employment forms. Today, information and com-

\footnotetext{
${ }^{1}$ Reprinted with permission from Forestry \& Forest Products International.
}

as well as how firms conduct business, governments govern and criminals commit crimes. Changes brought on by one group may result in benefits to that group but increase the risk or cost to others. After all technical knowledge is amoral; we as individuals or collectively as citizens decide on its proper or improper use.

\section{Information and Communication Technology and Forestry}

Most people think of forestry as a resource-based industry. However, information and communication technologies have been an integral part of forestry for a long time. They were necessary to develop and implement medium- and long-term plans for protection, access, harvest, manufacture, regeneration and maintenance. Forestry is really a knowledge-based resource industry. The sooner this is recognised by governments and the corporate world the better it will be for the forest sector and the quality of life in any forest nation.

Recognising forestry as a knowledge-based resource industry means that governments need to ensure its policies in trade, education, employment and regional development reflect this reality. Consider skills training for forestry workers. The current focus in Canada has been mostly on worker safety training. During times of acute unemployment make-work and literacy programs are often instituted. Missing are programs designed to improve worker knowledge of forest ecosystems. This can be done rapidly and at reasonable costs in conjunction with educational institutions, private enterprise and worker unions through the use of information and communication technology.

The advent of electronic information technologies has resulted in the conversion of older manual or mechanical technology to an electronic base. For example, forest inventories are now stored, manipulated and retrieved electronically rather than being stored and retrieved on paper ledgers and manipulated manually on paper spread sheets. This change from manual or mechanical means to electronic means of work is one of the changes occurring today. 
Another type of change occurring as a result of new information technology is the realisation that economies of scale can be achieved in the collection, manipulation, retrieval and dissemination of information through the use of compatible hardware and software. For example, data on timber, habitat and cultural values data can be collected simultaneously, and used by government and industry forest planners, and the public. Once compatible databases and comprehensive information systems have been developed they may lead to the development of new ways of doing work. That is, it may result in new types of work.

\section{Continuing to Reduce Forestry Information Costs}

If forest nations are to maintain or improve their quality of life, they need to use their scarce public and private resources wisely. As stated at the beginning of this article, the reduction in information costs is probably a major factor in the current economic boom. What, if anything, can be done to ensure information costs keep dropping?

When one considers the various types of hardware and software being used in forestry today one realises that data compatibility is a major cost, certainly more costly than fixing any Y2K bug! Transferring data from one software source to another may be impossible or require a great deal of labour. Anyone who has considered using data collected a decade or more ago recognises the costs associated with such ventures. We can expect changes in hardware and software to continue into the future. Will this lead to data incompatibility? Probably, but fortunately there is an answer.

Most people have probably heard of Hypertext Markup Language, usually referred to by its acronym HTML. This is the extremely popular electronic publishing language that allows web browsers in our computers to format text, images and clickon buttons on a web page. The language enables web sites to function as a fancy fax machine that sends electronic documents to anyone that asks. Today another language called Extensible Markup Language (XML) is doing for data what HTML did for text.

XML enables web sites to recognise the type of data being sent. It will allow web sites to take orders from customers, transmit complex and large data sets anywhere in the world, allow receivers to recognise and use the data, and will probably even run equipment remotely. Using a data Markup Language has another value. It will enable future computers and their software to recognise the significance of each datum.

Some professions have already started to harness the power of XML. Geneticists are starting to use Biosequence Markup Language to exchange and analyse the huge amounts of data generated by gene-mapping projects around the world. The National Aeronautics and Space Administration in the United States has started to develop Astronomical Instrument Markup Language which will one day allow ground-based scientists to control telescopes and possibly satellites through their Internet browser software.

The forest sector and government agencies should develop a Forest Markup Language. This language will allow forestry data to be shared among willing partners, eliminate obsolescence and create opportunities for new forestry applications that cannot even be imagined today.

The development of Forest Markup Language must be done in a co-operative manner, as the language should serve all users for a very long time. Forest Markup Language will involve the development of tags that, when linked to data, describe the meaning of that data. For example, a tag for diameter-breastheight in centimetres may be $<\mathrm{dbh} c \mathrm{~m}\rangle$. Instructions can be written into any database or web browser software to recognise the value associated with the tags and value. The tags and value associated with $<\mathrm{dbhcm}>28<\mathrm{dbhcm}>$ would be recognised as diameter-breast-height is equal to 28 centimetres

\section{A Global Challenge - Strategic Use of Scarce Public and Private Resources}

As stated earlier, information and communication technology provides us with the ability to synthesize and manipulate vast amounts of data in very short periods of time. This has resulted in the development and use of several strategic and predictive models of forests and other ecosystems. These models are used to evaluate the consequences of several management scenarios allowing decision-making to become more rational and thorough.

Consider now the response by nations to environmental change globally, nationally or regionally. In most cases our responses have been reactive and often confrontational. These responses have lead to specific programs on certain issues such as climate change, biodiversity loss, ozone depletion, forest fragmentation, etc.

Other approaches need to be investigated if we are to use scarce public and private resources wisely. One new approach that needs to be investigated is a global environmental assessment. This assessment would make use of current programs (such as those on climate change and loss of biodiversity), current knowledge, data and information and communication technology to provide citizens and their leaders with base line information and consequences of various realistic scenarios that may occur in the near future. The results could then be used to develop strategies to prevent known negative consequences. This comprehensive study could be repeated periodically to indicate how well-planned programs were being implemented and determine if they were meeting their mark at preventing known negative consequences. Such a program would allow resources to be used strategically by targeting the areas where the consequences would be the gravest.

\section{Conclusion}

Today's technology makes us vulnerable to major risk; our efficiency in exploiting natural resources, for example, has already led to major environmental and human calamities. Technology also provides us with the tools to deal with many of these problems. In particular, information and communication technology can be used to harness our existing knowledge to predict and prevent or mitigate negative consequences. Those involved in forestry can seize a leadership role in addressing the issues we face in the new millennium.

\section{What is the Canadian Institute of Forestry / Institut forestier du Canada?}

The Canadian Institute of Forestry / Institut forestier du Cana$\mathrm{da}(\mathrm{CIF} / \mathrm{IFC})$ is a national voice for forestry professionals in Canada. The CIF/IFC, formed in 1908, has over 2,400 members organised in 23 sections across Canada representing 
members who are scientists, academics, technicians, technologists, foresters and professionals with an interest in the well-being of the forest. The Institute's mission is "to provide national leadership in forestry, promote competence among forestry professionals, and foster public awareness of Canadian and international forestry issues."
CIF/IFC members may also voluntarily belong to Working Groups. Each Working Group addresses the interests of its members in a specific subject such as forestry education, private land forestry, silviculture, or information technology.

Visit our website: www.cif-ifc.org 